\title{
-
}

ISSN 2278-0211 (Online)

\section{Optimization of Percentage Dilution in Butt Welds to Prevent Weld Porosity Using Response Surface Methodology}

\author{
Dr. Queeneth Adesuwa Kingsley-Omoyibo \\ Lecturer, Department of Mechanical Engineering \\ Igbinedion University Okada Edostate, Nigeria
}

\begin{abstract}
:
A detailed analysis to optimize percentage dilution in butt welds in order to prevent weld porosity has been carried out in this study. The response surface steepest ascent was used to optimize values of percentage dilution in a butt weld using gas tungsten arc welding process. Predictions for percentage dilution were made using the second order mathematical model for response surface methodology and results obtained showed that percentage dilution value of $45.73 \%$ was able to eradicate weld porosity in butt welds. Overall results of percentage dilution analyzed, recorded an optimal value of $45.73 \%$ with values of welding current, welding voltage and welding speed as 131.5 amperes, 17.4 volts and $100 \mathrm{~mm} / \mathrm{min}$ respectively. A defined quantity of percentage dilution value of $45.73 \%$ established in this study should be used at a GTAW process to provide sufficient amount of dilution for controlled solidification of molten metal during welding operation in order to produce porosity-free welds. This work presented results that revealed percentage dilution values that will prevent weld porosity in butt welds with no gas traps or voids in welded joints produced.
\end{abstract}

Keywords: Percentage dilutions, Butt welds, steepest ascent, Weld porosity, Response Surface Methodology, gas tungsten arc welding process

\section{Introduction}

Based on the absence or presence of welding defects such as weld porosity in the welded joints, fabrication process of the welds depends on the quality of welded structures. Porosity in welded joints affects negatively, all welded structure performance and this may lead to failure in the welded structure. This study deals with the prevention of weld porosity using an optimized value of percentage dilution (Moreno, 2013). Weld Porosity is a defect that arises during welding process due to the presence of gas pockets in welded metals, causing cavities and small holes inside the welds, resulting in failure in design and service life reduction of welds. Gas line leaks and massive turbulence in weld pool are common causes of porosity that occurs when joints are improperly prepared and use of too long arc length during welding. Other reasons for porosity to occur are too greasy and dirty Surface of work place to be welded, wet electrodes, low heat input, voltage too low, gas flow rate too low and speed also too low (Mostafa,2006). All electrodes must be kept dry always, using sufficient heat input with increased amperage at a Gas Tungsten Arc Welding process. This action will produce a good fusion between the welded joint and the base metal. When Porosity is noticed on a welded metal, the welded joint is chipped and welded again (Parmar, 2013). Ginzel, 2002classified porosity into warm and spherical holes, stating that porosity is caused when argon shielding gas, does not completely reach the weld pool due to high travel speed, very high current and very low gas flow rate. In order to reduce the risk of weld porosity, cooling rate is retarded with a decrease in welding speed, by allowing gas to escape. This action will increase heat input and produce a specified quantity of percentage dilution $(\% \mathrm{D}$ that in turn prevent the occurrence of Porosity (Harris, 1998).

Base metals welded, having presence of gas pockets appearing on the welded joints is as a result of porosity defect. The presence of porosity has resulted in weld defects such as cracking, distortions, Spatter and undercut inclusive. Weld porosity prevention using the adequate value of percentage dilution was investigated and results of percentage dilution were recorded at 47.61\% (Dinesh et al., 2012).

Technological advancements in the welding industries have caused an increase in weld defect avoidance and weld quality enhancement. This increase in welding technology enhancement specifically using gas tungsten arc welding (GTAW) process has been sparsely satisfied by heat input of the welding process, particularly heat affected zone (HAZ) and a percentage dilution of $46.97 \%$ was recorded after a rigorous investigation performed (Kluken, 1994). Dilution rate at a weld is affected by the volume of shielding gas in the puddle with a release of gas to the atmosphere. Reduction in shielding gas volume investigation showed low weld porosity with a percentage of 45.95\% (Pedro, et al., 2009). Reintroduction of an optimization technique resulted in a highly productive welding method in which the dabbing technique used in a Gas Tungsten Arc Welding (GTAW) process was used to join plates of thickness of a $10 \mathrm{~mm}$ mild steel plate. During the GTAW process, gases were trapped inside the weld resulting in the presence of holes, voids and cavities in the joints welded (Juang, 2002). A controlled progression cooling process in a weld pool will prevent occurrence of weld 
porosity with a percentage dilution of $45.70 \%$ (Hari, et al 1998). Weld porosity is solely dependent on percentage dilution, as a defined amount of percentage dilution will help to prevent weld porosity in welded components (Kumari, et al 2013). Percentage dilution is the ratio of reinforcement area to total weldment area. Welding speed, welding current and welding voltage are input process parameters that affect percentage dilution and a percentage dilution value of $46.05 \%$ was recorded from investigation (Kumari et al., 2013). This study investigates input process parameters such as welding current, welding voltage and welding speed with gas flow rate from the shielding gas kept constant at 16 lit/min. Point predictions of percentage dilution using actual coding with standard deviation were recorded using the design expert software.

\section{Methodology}

\subsection{Response Surface Methodology (RSM)}

The study analyzed data using Response Surface Methodology (RSM), which is influenced by input parameters with an objective to obtain a relationship amongst responses and the input parameters alongside the optimization of the responses using statistical techniques were investigated (Kannan, 2010). Response Surface Methodology (RSM 2 model is written as:

$Y=\left(X_{1}, X_{2}, X_{3}, X_{4} \ldots X_{n}+\varepsilon\right.$

$\mathrm{Y}=$ responses

Where $\varepsilon=$ random error or noise factors in the response

$\mathrm{X}_{1}-\mathrm{X}_{\mathrm{n}}=$ input process parameters

The response surface $=Y=f\left(X_{1}, X_{2}, X_{3} \ldots X n\right)$

Using a second order model (Correia et al., 2005).

Using a regression model with coefficient estimate, equation 1 and 2 , is used to analyze the system.

$Y=\beta_{o}+\sum_{i=0}^{k} \beta_{i} x_{i}+\sum_{i=0}^{k} \beta_{i} x_{i}^{2}+\sum \sum_{i<1} \beta_{i j} X_{i j}+\varepsilon$

$\mathrm{Y}=\mathrm{f}\left(\mathrm{X}_{1}+\mathrm{X}_{2}\right)+\varepsilon_{i} \quad$ (regression model)

Where $\varepsilon_{i}=$ random error

RSM Model helps to analyze the surface plot with topography in order to obtain optimal design and confirm the optimal design using stationary point.. Using the second order model and a multiple non-linear regression analysis: Three factors (welding current, welding voltage, welding speed and gas flow rate kept constant, with the response: percentage dilution (\%D) was analyzed.

\subsection{Experimental Procedures}

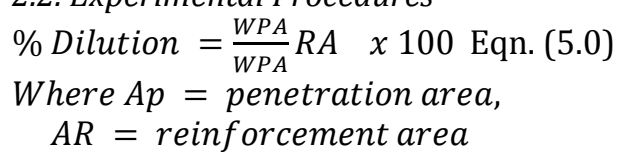

(Dinesh et al. , 2012).

Using designated formula , $\% D=$ percentage dilution ( $\mathrm{mm} 2$ )

$\%$ Dilution $=\frac{W P A}{A T} \times 100$

Where $A T=$ Total weldment area $(A P+A R)$

\subsection{Welded Plate Production}

The $10 \mathrm{~mm}$ mild steel plates used were obtained from scrap yard located at Igun Street (Bronze casting center area) Benin City, Edo State of southern Nigeria. A multipurpose ESAB welding machine using a direct current straight polarity welding current type was used. An electrode ER 70 S6 was used to achieve deep and a narrow profile for penetration. A Total of 16 specimen plates were cut using an automated gas cutting machine to produce the sections of the plates. Grinding was done to remove the cooled work deposited on the mild steel plates. The rough specimens were polished by hand, using abrasive papers. After etching the specimens with a $50 \mathrm{ml}$ hydrochloric acid and $10 \mathrm{ml}$ distilled water to reveal the bead profile, the profile projector was used to view the bead profile after etching. The 16 butt joints prepared samples were merged to form 8 test specimens for welding. The welding using GTAW process was done in the welding workshop of Petroleum Training Institute (PTI) in Warri, Delta state, Nigeria. 


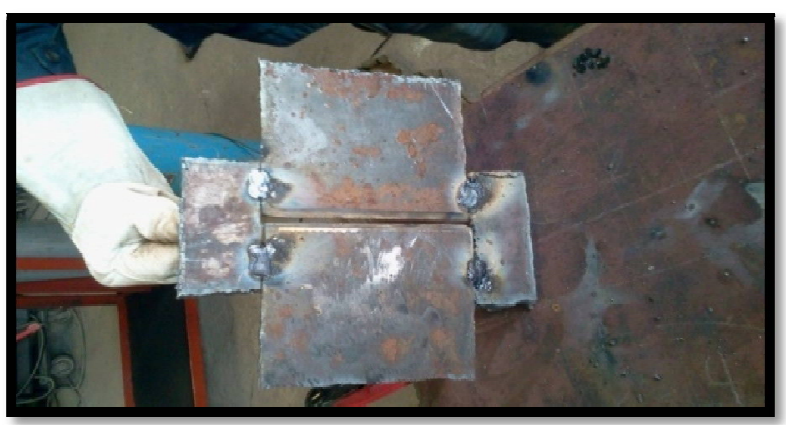

Figure 1: A Tacked Butt-Joint with 3mm Root Gap

Before taking the 8 specimens, a $3 \mathrm{~mm}$ gap was used at a GTAW process. The first bead was deposited (root pass) into the root gap and then the hot pass, fill pass and lastly the cap pass which is finally used to cover up the groove and give a good bead geometry. The width of the bead was recorded using a $0.02 \mathrm{~mm}$ least count Vernier caliper,

Height of bead was in millimeters, the reinforcement area of the bead welded into the v-groove shaped mild steel plate was recorded using the profile bead projector and the digital plannimeter. The values recorded were later used to calculate for percentage dilutions (Kumari et al., 2013). The percentage dilution of the weld puddle for all 8 specimens welded was calculated using equation (7).

\subsection{Optimization Using Response Surfac Methodology}

Minimizing Percentage Dilution (\%D) with respect to constraints, using

Min. $\% \mathrm{D}=\mathrm{f}(\mathrm{I}, \mathrm{V}, \mathrm{S}$,

Min. $\% D=\beta_{0}+\beta_{1} I+\beta_{2} V+\beta_{3} S+\beta_{2} I V+\beta_{13} I S+\beta_{23} V S$

Eqn. (6.0.)

s.t

$90 \leq \mathrm{I} \leq 160$

$10 \leq \mathrm{V} \leq 18$

$80 \leq \mathrm{S} \leq 100$

To reduce the risk of failure in design due to weld porosity in welded joints using the input parameters such as welding current, welding voltage and welding speed to obtain a response such as percentage dilution, a low welding speed of 100 $\mathrm{mm} / \mathrm{min}$ was used to control a progressive cooling using a not too high current of 131.5 ampere and a medium voltage of 17.4 volts to avoid undesirable phase formation in welds. The solidification rate in the weld pool of the welded butt joint (V-groove) was determined using the equation 1. Percentage dilution results were recorded using critical parameters such as reinforcement area and weld penetration. A defined quantity of percentage dilution value of $45.73 \%$ was established. Hence, percentage dilution was determined using equation 7 (Dinesh, 2012).

\section{Results and Discussion}

\subsection{Results of Percentage Dilution}

Using designated formula, $\% D=$ percentage dilution (\%)

$\&$ Dilution $=W P A / A T \quad x 100($ Dinesh, 2012). Eqn. (7)

Where $A T=$ Total weldment area $(A P+A R)$

Where $W P A=20.85 \mathrm{~mm}, R A=24.75 \mathrm{~mm}$

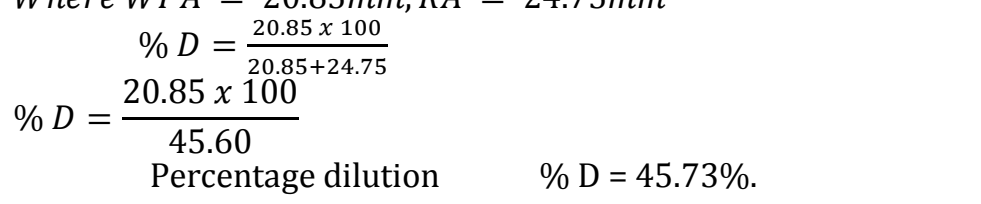

\begin{tabular}{|c|c|c|c|c|c|c|}
\hline \multirow[t]{2}{*}{ S/N } & \multirow[t]{2}{*}{$\begin{array}{l}\text { Reinforcement } \\
\text { area }\left(\mathrm{mm}^{2}\right)\end{array}$} & \multirow{2}{*}{$\begin{array}{c}\text { Weld } \\
\text { penetration } \\
\text { Area }\left(\mathrm{mm}^{2}\right) \\
\end{array}$} & \multirow{2}{*}{$\begin{array}{c}\text { Total } \\
\text { weldment } \\
\left(\mathrm{mm}^{2}\right)\end{array}$} & \multicolumn{3}{|c|}{$\begin{array}{c}\text { Error Analysis } \\
\text { Percentage dilution (\%D) }\end{array}$} \\
\hline & & & & Actual values & Predicted values & Error (Ei) \\
\hline 1 & 24.55 & 20.54 & 45.00 & 45.66 & 45.64 & 0.02 \\
\hline 2 & 24.80 & 21.00 & 45.80 & 45.86 & 45.83 & 0.03 \\
\hline 3 & 25.33 & 21.64 & 47.90 & 45.00 & 45.00 & 0.00 \\
\hline 4 & 25.25 & 20.38 & 44.30 & 45.95 & 44.93 & 0.02 \\
\hline 5 & 23.92 & 20.38 & 44.30 & 45.99 & 44.93 & 0.06 \\
\hline 6 & 24.05 & 20.35 & 44.40 & 45.81 & 43.80 & 0.01 \\
\hline 7 & 26.60 & 21.70 & 48.30 & 44.91 & 45.89 & 0.02 \\
\hline 8 & 23.29 & 20.51 & 44.80 & 45.88 & 45.87 & 0.01 \\
\hline
\end{tabular}

Table 1: Reinforcement, Percentage Dilution and Weld Penetration Area Values 


\subsection{Discussion of Results}

\subsubsection{Comparison of Reported Literature Values}

The response and percentage dilution (\%D) obtained, by different researchers are as presented in Table 1 . The result obtained for the percentage dilution, $45.73 \%$, is almost equivalent to $45.70 \%$ recorded in the work of Hari et al (1998). The variations in percentage dilution may have been as a result of the difference in variety of methodology used, data collection and analysis of results. The percentage dilution from moderate welding speed, with a progressive cooling in the weld pool was $45.73 \%$. It compares favorably with authors such as Pedro et al., (2009) with $45.95 \%$ and Kumari et al., (2013) with $46.05 \%$. Studies have also shown that the methodology, the input process parameters in the right proportion and the model used, are very important operational parameters which have significant impact on the percentage dilution of $47.61 \%$ (Dinesh, 2012). A controlled solidification of molten metal during welding operation required is achieved with current of 131.5 amperes, 17.4 volts and $100 \mathrm{~mm} / \mathrm{min}$ speed in this research as compared to 140 amperes, 18 volts and $101.1 \mathrm{~mm} / \mathrm{min}$ speed as recorded by Dinesh et al., (2012).

\begin{tabular}{|c|c|c|c|}
\hline $\begin{array}{c}\text { Response Percentage } \\
\text { dilution (\%D) }\end{array}$ & Values recorded & $\begin{array}{c}\text { Reported values in } \\
\text { literature }\end{array}$ & References \\
\hline Percentage dilution (\%) & By author, Omoyibo & $47.61 \%$ & Dinesh et al., (2012) \\
\cline { 3 - 4 } & $(2020)$ & $46.98 \%$ & Kluken et al (1994) \\
\cline { 3 - 4 } & $45.73 \%$ & $45.95 \%$ & Pedro et al., (2009) \\
\cline { 3 - 4 } & & $45.70 \%$ & Hari et al (1998) \\
\cline { 3 - 4 } & & $46.05 \%$ & Kumari et al., (2013) \\
\hline
\end{tabular}

Table 2: Comparison of Reported Literature Values vs. Author's Value for Percentage Dilution

\begin{tabular}{|c|c|c|c|c|}
\hline $\begin{array}{c}\text { Experimental } \\
\text { runs }\end{array}$ & $\begin{array}{c}\text { Welding current (I) } \\
\text { Amp (I) }\end{array}$ & $\begin{array}{c}\text { Welding } \\
\text { voltage volts } \\
\text { (V) }\end{array}$ & $\begin{array}{c}\text { Welding speed } \\
\mathbf{m m} / \mathbf{m i n} \text { (S) }\end{array}$ & $\begin{array}{c}\text { Percentage } \\
\text { dilution (\%) }\end{array}$ \\
\hline 1 & 132.77 & 17.94 & 99.89 & 45.88 \\
\hline 2 & 132.58 & 17.20 & 80.07 & 44.91 \\
\hline 3 & 137.19 & 17.89 & 69.68 & 45.66 \\
\hline $4 *$ & 131.50 & 17.40 & 100.00 & $45.73^{*}$ \\
\hline 5 & 130.00 & 16.57 & 80.00 & 45.99 \\
\hline 6 & 130.02 & 15.20 & 98.40 & 45.81 \\
\hline 7 & 140 & 17.91 & 87.98 & 45.86 \\
\hline 8 & 150 & 18.0 & 99.91 & 45.95 \\
\hline
\end{tabular}

Table 3: Observed Values for Bead Parameter for Percentage Dilution Analysis (Full Experimental Analysis Results)

\begin{tabular}{|c|c|c|c|}
\hline S/N & Percentage Dilution (\%D) & Desirability Value & Selected \\
\hline 1 & 45.73 & 1 & \\
\hline 2 & 45.66 & 1 & \\
\hline 3 & 45.81 & 1 & \\
\hline 4 & 45.76 & 1 & \\
\hline 5 & 45.24 & 1 & \\
\hline 6 & 45.75 & 1 & \\
\hline 7 & 45.91 & 1 & \\
\hline 8 & 45.27 & 1 & \\
\hline
\end{tabular}

Table 4: Showing Desirability Values for Percentage Dilution Optimal Values

Table 4 showed recorded values of percentage dilution, the desirability values in the values of 1 , and the selection of $45.73 \%$ as the desired optimum percentage dilution value.

\subsubsection{Point Prediction for Percentage Dilution}

Point prediction for percentage dilution with a square mean error of 0.2612 and a square error prediction of 0.4755 actual coding were used with a standard deviation of zero using high (+) and low (-) level (Ibrahim IBN, 2009). A value of $44.91 \%$ was obtained at the low confidence interval of $95 \%$ while the $95 \%$ high confidence interval recorded a value of $46.98 \%$ based on all of these predictions. Predictions for percentage dilution for optimal value were obtained using values of $45.72 \%$ as a guide. 


\begin{tabular}{|c|c|c|c|c|c|c|c|}
\hline Factor & Notation & Units & & $\begin{array}{c}\text { Low level } \\
(-)\end{array}$ & $\begin{array}{c}\text { High level } \\
(+)\end{array}$ & Std. Dev. & Coding \\
\hline $\begin{array}{c}\text { Welding } \\
\text { current }\end{array}$ & $\mathrm{I}$ & Amperes & 130.06 & 90 & 160 & 0 & Actual \\
\hline $\begin{array}{c}\text { Welding } \\
\text { voltage }\end{array}$ & $\mathrm{V}$ & Volts & 17.29 & 10 & 18 & 0 & Actual \\
\hline $\begin{array}{c}\text { Welding } \\
\text { speed }\end{array}$ & $\mathrm{S}$ & $\mathrm{mm} / \mathrm{min}$ & 81.13 & 80 & 100 & 0 & Actual \\
\hline Response & Prediction & & SE mean & $95 \%$ CI low & $\begin{array}{c}95 \% \mathrm{CI} \\
\text { High }\end{array}$ & SE Pred. & $\begin{array}{c}95 \% \text { PI low } \\
\text { /95\%PI high }\end{array}$ \\
\hline \% Dilution & 45.72 & & 0.2162 & 45.46 & 45.98 & 0.4755 & $\begin{array}{c}44.91 \text { low } \\
46.98 \text { high }\end{array}$ \\
\hline
\end{tabular}

Table 5: Point Predictions for Percentage Dilution

Data used for reinforcement area (AR) measured in square millimeters $\left(\mathrm{mm}^{2}\right)$ were recorded from the measurements taken from the profile projector data processing units and the digital plannimeter and presented in Table 3. This was used to determine the value for the total weldment and eventually used to calculate for the percentage dilution as shown in equation 7. From the eight (8) experimental runs, the estimated value for percentage dilution (\%D) was $45.72 \%$. A design of experiment (DOE) for a Response Surface Methodology (RSM) was used to predict the percentage dilution (\%D). A two level, three factor design was used. The linear and interactive effect of the input process parameters was analyzed using the design expert software.

Model: $Y=\% D=\beta o+\sum_{i=o}^{k} \beta i X i+\sum_{i=o}^{k} \beta_{i} X_{i}+\sum \sum_{i<j} P_{i j} X_{i j}+\epsilon$

$\% \mathrm{D}=\beta o+\beta_{1} I+\beta_{2} V+\beta_{3} S+\beta_{12} I V+\beta_{23} V S+\beta_{13} I S+\varepsilon_{i}$

Min $\% \mathrm{D}=\mathrm{F}(\mathrm{I}, \mathrm{V}, \mathrm{S})$

Where: $\mathrm{I}=$ current $\mathrm{V}=$ voltage and $\mathrm{S}=$ speed

$\beta_{0}=$ free regression coefficient / intercept

$\varepsilon_{i}=$ Error

Where $\beta_{\mathrm{o}}=45.73$ and $\varepsilon i=0.02$

Constraints $\beta_{1}-\beta_{23}=$ regression coefficient for interaction effects for IV, IS and VS.

S.t $\% \mathrm{D}($ Minimize)

I $\min \leq \mathrm{I} \leq \mathrm{I} \max \quad$ i.e. $90 \leq I \leq 150$ amperes

$\mathrm{V} \min \leq V \leq V \max$ i.e $10 \leq V \leq 18$ volts

$S \min \leq S \leq S \max$ i.e. $60 \leq S \leq 100 \frac{\mathrm{mm}}{\mathrm{min}}$.

\subsubsection{Response Surface Model for Percentage Dilution (\%D)}

The obtained coefficient of regression for response surface regression model for percentage dilution \%D were processed as shown in equation 3 and equation 6 , for the three input process parameters namely welding current (I), welding voltage $(\mathrm{V})$ and Welding Speed (S).

\begin{tabular}{|c|c|c|c|c|c|c|c|c|c|}
\hline \multirow[t]{2}{*}{$\mathbf{S} / \mathbf{N}$} & \multirow{2}{*}{$\begin{array}{l}\text { Coefficient of } \\
\text { regression } \beta 0\end{array}$} & \multirow[t]{2}{*}{$\beta_{0}-\beta_{23}$} & \multirow{2}{*}{$\begin{array}{l}\text { Percentage } \\
\text { dilution } \\
\text { (\%D) }\end{array}$} & \multicolumn{3}{|c|}{ Experimental matrix } & \multicolumn{3}{|c|}{ Design matrix } \\
\hline & & & & I & $\mathbf{V}$ & $S$ & I & $\mathbf{V}$ & $S$ \\
\hline 1 & $\beta_{0}$ & 45.730 & 45.730 & 150 & 18 & 100 & + & + & + \\
\hline 2 & $\beta_{1}$ I & -0.070 & 45.660 & 150 & 18 & 60 & + & + & - \\
\hline 3 & $\beta_{2} \mathrm{~V}$ & +0.080 & 45.810 & 150 & 18 & 100 & + & + & + \\
\hline 4 & $\beta_{3} \mathrm{~S}$ & +0.030 & 45.760 & 150 & 18 & 100 & + & + & + \\
\hline 5 & $\beta_{12}$ IV & -0.490 & 45.240 & 90 & 10 & 60 & - & - & - \\
\hline 6 & $\beta_{13}$ IS & +0.020 & 45.750 & 90 & 10 & 60 & - & - & - \\
\hline 7 & $\beta_{23} \mathrm{VS}$ & +0.180 & 45.910 & 90 & 10 & 100 & - & - & + \\
\hline 8 & - & - & - & 90 & 10 & 60 & - & - & - \\
\hline
\end{tabular}

Table 6: Response Parameters and Significant Coefficient of the Model for $\% D$

$$
\varepsilon=\text { Coefficient Estimate }=45.73 \%
$$

The coefficient intervals were determined using the coefficient estimates and values. Percentage dilution as shown in Table 5 decreased by 0.070 units when welding current (I) decreased by unity will all other factors kept constant to give $45.6 \%$. Percentage dilution increased by 0.088 units when welding voltage increased by unity to give $45.8 \%$. Percentage dilution increased by 0.037 units as welding speed increased by unity to give $45.7 \%$. Percentage dilution decreased by 0.487 units when the interaction between welding current and welding voltage decreased by unity to give 45.2\%. percentage dilution increased by 0.024 units as the interaction between welding current and welding speed increased by unity to give $45.7 \%$. Lastly, percentage dilution increased by 0.188 units as welding voltage and welding speed interaction increased by unity to give $45.9 \%$. The signs for welding current, welding voltage and welding speed as 
shown in Table 5, are - , + and + respectively. Indicating that welding current was not too high but controlled, welding voltage was high and welding speed was high at a gas tungsten arc welding and this yielded a percentage dilution between $45.2 \%$ - 45.9\%. The coefficient estimate was $\varepsilon=45.73 \%$ as calculated from Table 5. Table 6 was used to present desirability values for percentage dilution optimal values. All the desirability values of percentage dilution values in Table 6 and that in Table 4, all had values of 1 indicating that the model in equation 3.2 and equation 3.3 is a fit model and also the model is significant. Interaction between welding current and welding voltage showed actual factors of welding speed as $100 \mathrm{~mm} / \mathrm{min}$ with welding voltage and welding current recorded as 17.5 volts and 130.7 amperes respectively.

\subsubsection{Response Surface Plots for Percentage Dilution}

Response surface plots for percentage dilution analyzed the results with a goal to minimize percentage dilution in order to obtain a defined quantity of percentage dilution (\%) that will be used to prevent weld porosity. Figure 2 shows the Interaction surface plots of percentage dilution showing current vs. Gas flow rate with every other factor kept constant.

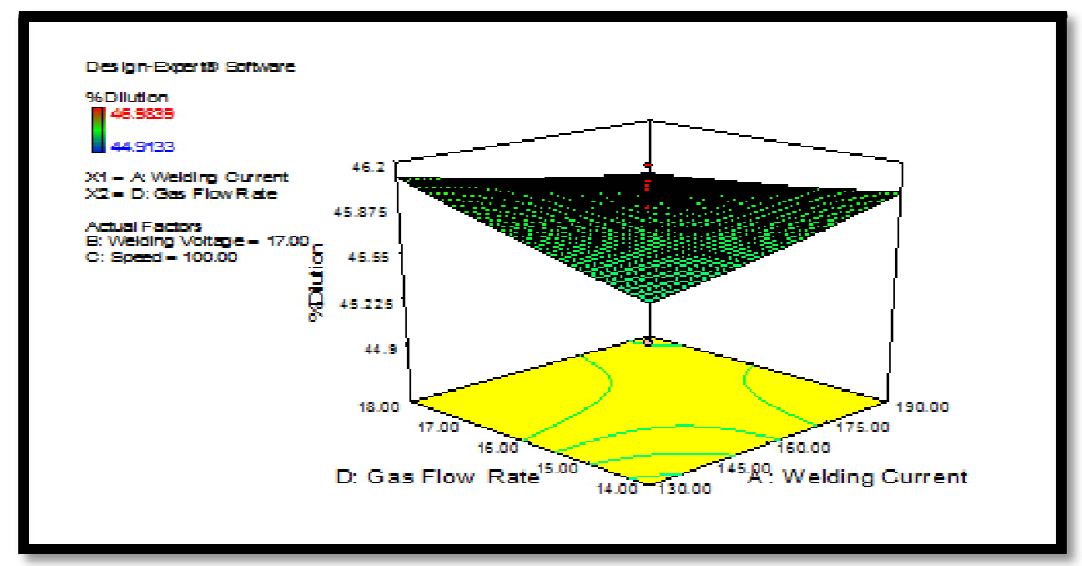

Figure 2: Interaction Surface Plots of Percentage Dilution Showing Gas Flow Rate vs. Welding Current

As presented in figure 2, a welding current of 130 amperes with a welding voltage of 17 volts and welding speed of $100 \mathrm{~mm} / \mathrm{min}$ produced a percentage dilution of $45.6 \%$. As welding current increased, the welding voltage also increased with a speed that produced a controlled solidification of molten metal at the weld pool that was free from presence of gas pockets at the welded joints. Figure 2 steepest ascent interpretation is a saddle point.

Figure 3 shows Interaction surface plots of percentage dilution showing current vs. speed with every other factor kept constant. As presented in figure 3, a welding current of 132.7 amperes, with a welding speed of $99.89 \mathrm{~mm} / \mathrm{min}$ and a voltage of $17.00 \mathrm{v}$ produced a percentage dilution value of $45.8 \%$, welding voltage is inversely proportional to welding speed, hence as welding speed increase welding voltage decreased using 17 volts. The steepest ascent interpretation for figure 3 is a ridge point.

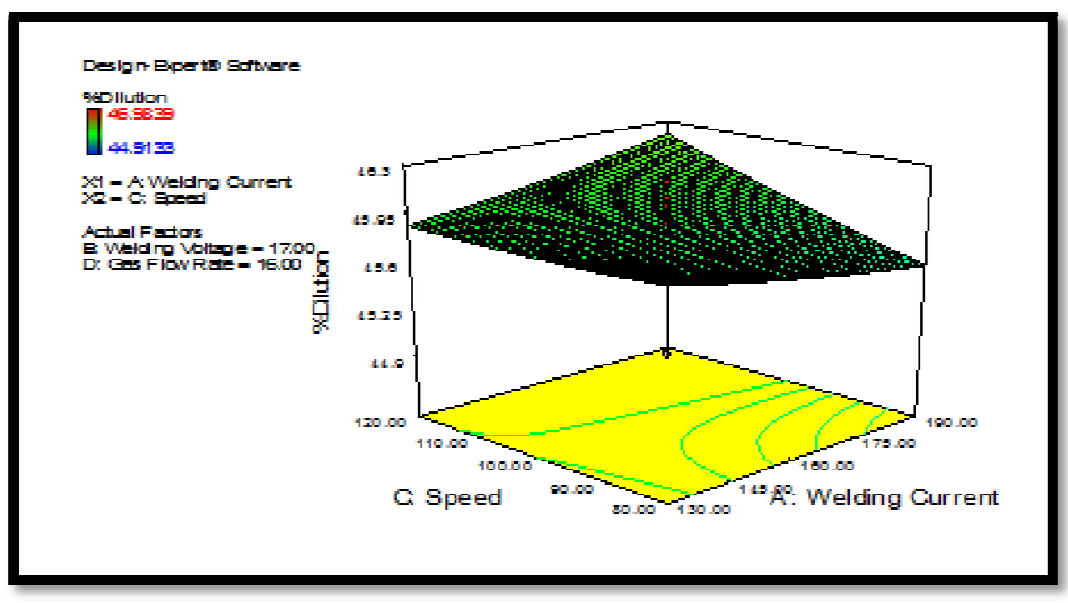

Figure 3: Interaction Surface Plots of Percentage Dilution Showing Speed Vs. Welding Current

Showing the Interaction surface plots of percentage dilution showing voltage vs. speed is Figure 4, with every other factor kept constant. As presented in figure 4, a welding voltage of $17 \mathrm{volts}$ minimized the percentage dilution at a value of $46.2 \%$ with a welding current of 160 amperes. The welding speed applied at $90 \mathrm{~mm} / \mathrm{min}$ produced a welding voltage inversely proportional to welding speed, hence a decrease in welding speed, produced a high voltage of $17 \mathrm{volts}$ with a controlled cooling of molten metal to produce a percentage dilution value of $46.2 \%$. 


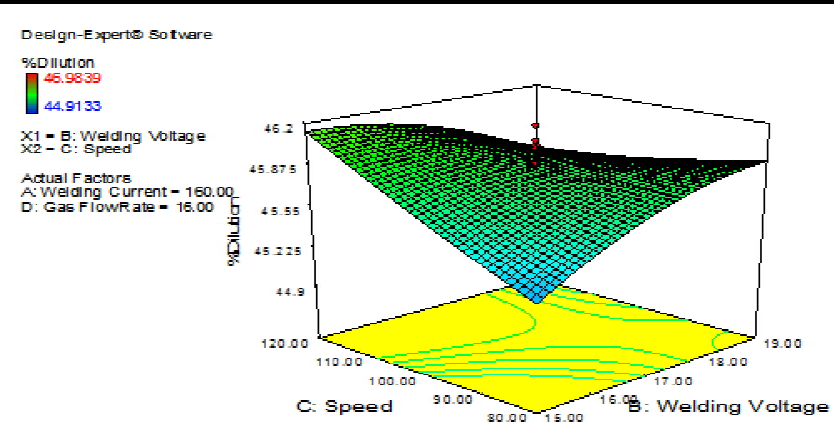

Figure 4: Interaction Surface Plots of Percentage Dilution Showing Speed Vs. Voltage

The steepest ascent interpretation for figure 4 is a saddle point.

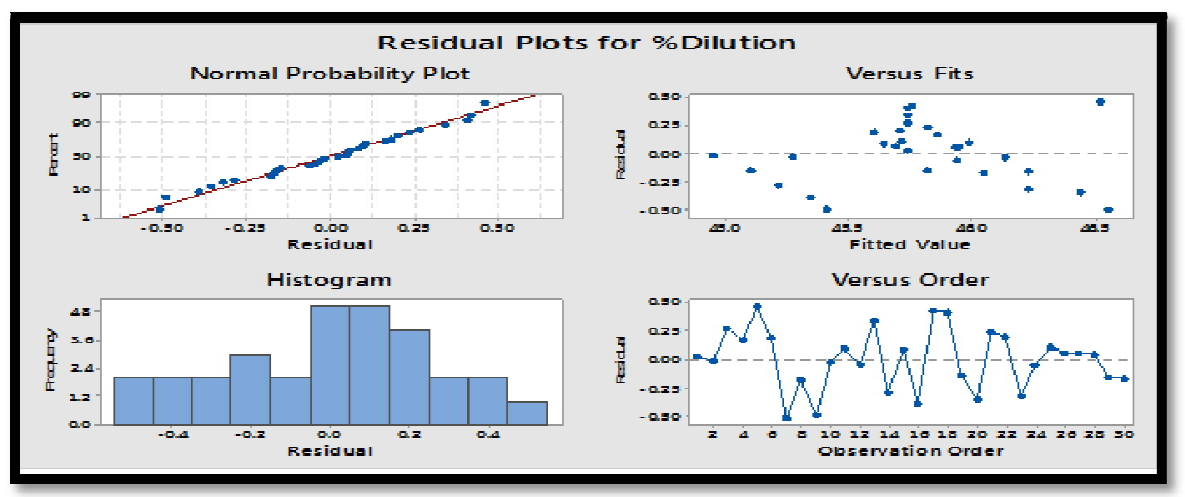

Figure 5: Residual Plot for Percentage Dilution

Showing a four- in - one normal probability plot for percentage dilution is Figure. 5. The plots of residual versus observation order for percentage dilution are randomly scattered about the zero axis which indicates that assumption of constant variation considerably holds. The residual plots show the normal probability plot, fitted value plot, histogram plot and the observation order plot which represents the data obtained from the responses and can be used for statistical modeling.

\subsubsection{Percentage Dilution Scatter Plot}

From the plot of predicted values of percentage dilution(\%D) against actual values of percentage dilution (\%D), it can be deduced that the scatter plots are regular and all the values clustered around the mean values of percentage dilution indicating that all the error values were randomly distributed. This showed that there was an independent distribution of residuals with absence of outliers. The experimentally observed values and predicted values were used for graphical representation as shown in figure 6. The results closely agreed in some cases and deviated in other cases due to experimental errors indicating that the model requires no changes and all the error values were randomly distributed. It shows that the model is suitable and there is an independent distribution of residuals with absence of outliers. The data for percentage dilution (\%D) can be fitted into the linear model.

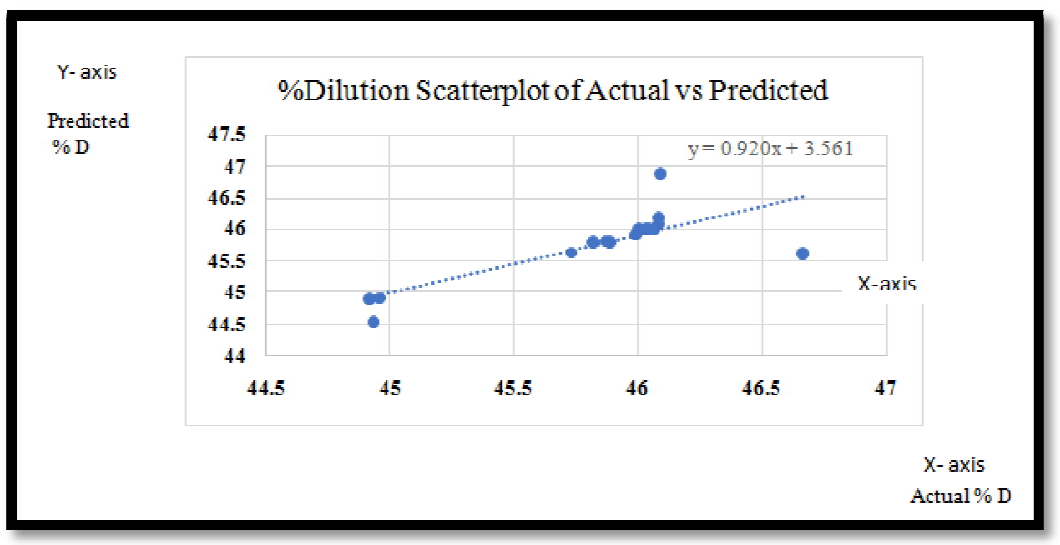

Figure 6: Plot of Predicted Values of Percentage Dilution (\%D) Against Actual Values of Percentage Dilution (\%D) 


\section{Conclusion}

This work presented results that revealed percentage dilution values that will prevent weld porosity in butt welds with no gas traps or voids in welded joints produced .optimized percentage dilution value for butt welds to prevent weld porosity was recorded at $45.73 \%$ with a low welding speed of $100 \mathrm{~mm} / \mathrm{min}$ for a progressive cooling of molten metal with a medium current of 131.5 amperes and a medium voltage of 17.4 volts at a gas tungsten arc welding process. A weld free from weld porosity (defect) resulted from a slow solidification rate in the weld pool for welded butt joint. All the input process parameters such as welding current, welding speed and welding voltage were within the specification of international standard (ASTM). Therefore, a defined quantity of percentage dilution with a value of $45.73 \%$ can be exploited for the prevention of weld porosity in butt welds using gas tungsten arc welding process. It is hoped that the application of percentage dilution of $45.73 \%$ obtained in this study by manufacturers and the welding industry will lead to the production of porosity -free welds and high-quality welds.

\section{References}

i. Dinesh K. and Sunil P. (2012) Dilution control by advanced SAW, International Journal of Advanced Materials Research. 488(489), Pp. 1737-1741.

ii. Ginzel, Edward. (2002). Pipeline Girth Weld Inspections Using Ultrasonic Phased Arrays. 10.1115/PVP2003-1848.

iii. Hari.O. and Pandey S. (2013) Effect of heat input on dilution and heat affected zone in sub-merged arc welding process, Indian Academy of Science 38 (6), Pp. 1369-1391.

iv. Harris J.O. (19198) A reviews of literature on porosity formation and recommendation on the avoidance of porosity in TIG welding. The Welding Institute.

v. Juang, S.C, and Tarang, Y.S, (2002) Process parameter selection for optimizing the weld pool geometry in the TIG welding of stainless steel. International Journal of material process technology, 122(1), Pp. 33 - 39.

vi. Kannan T. and Murunga., (2006) Effect of Flux core arc welding process parameters on duplex stainless-steel clad quality. Journal of material process technology 176, Pp. 230 - 239

vii. Kingsley- Omoyibo, Q.A., (2020) Optimization of Percentage dilution in Butt welds to prevent Weld porosity using Response Surface Methodology at a Gas Tungsten Arc Welding Process. International journal of innovative research and development. ISSN 2278 - 0211 Online.

viii. Kluken A.O., Edward G.R. and Hunt A.C. (1994) Heat input and Dilution effects in micro alloyed steel weld metals welding research supplement. Journal of material process technology

ix. ᄀKumari.P. Mohd. S. and Prarvez. M. (2013) Effect of MIG welding input process parameters on weld bead geometry on HSLA steel. International journal of engineering science and technology 1(1), Pp.200 - 215

x. Moreno, P. (2013) Welding defects (1st Edition) Aracne

xi. Mostafa, N.B., and Khajavi, M.N.,(2006) Optimization of welding parameters for weld optimization in FCAW journal of Achievements, materials and manufacturing engineering 16(1), Pp.1-12

xii. Parmar R.S. (2013) welding Engineering (1st Edition) Department of Metallurgical and Materials Engineering National Institute of Technology Tiruchirappalli -620 015.

xiii. Pedro P.R., (2009) measurement of weld dilution from images using active contours. SEECCM conference, Rhodes Greece, Pp. 22-24. 